\title{
nuestro peligro y nuestra salvación
}

En el principio era la forma. ¿Qué otra razón puede esgrimir una revista de gran difusión para que un arquitecto exponga en ella el tapiz mágico de su flosofía?

Y no le falta razón. A decir verdad, arquitecto equivale a comerciante en formas. Si lleva en su alma a un especialista eflcaz, es también un ingeniero. Pero si conflesa sin rodeos su amor por la forma, es, sobre todo, un verdadero arquitecto. $Y$ en las páginas que siguen, él-el arquitecto-va a exponeros, con franqueza, pequeños pensamientos que de vez en cuando acuden a su mente. Las sesudas revistas de economía comercial sólo admiten estadísticas económicas sobre nuestra cática-y proteica, al mismo tiempo-civilización occidental.

Figure, desgraciadamente, significa dos cosas en la equívoca ambigüedad de la lengua inglesa. Significa representación y significa simple y estéril figura geométrica, número.

¡Cuánta confusión entre lo antiguo y lo moderno!

He sido consejero en los mares del Sur y en Nigeria. Allí he conocido sitios donde sólo el jefe sabe contar más de tres. Pero las chicas que le ayudan están bien formadas, y se adornan con gracia: hecho éste al cual el jefe y todo el mundo es susceptible.

Durante cien mil años, el hombre ha sido feliz manejando contornos jugosos, formas imaginativas y diseños intrincados. Pero las áridas cifras, que son relativamente nuevas, y las distancias astronómicas, que escapan a nuestra comprensión, son la especialidad más característica de estos tiempos nuestros, en los cuales se envían cohetes a la luna. Sin necesidad de remontarnos a los espacios siderales, ya la misma tierra nos aturde con sus millones y millones de kilovatios, con sus millones de metros cuadrados, con sus caballos de vapor, sus unidades térmicas, sus fortunas en dólares, y sus pesadillas en forma de impuestos y cargas fiscales.

Sí, evidentemente, cuando la vida comenzó no existía un caos tan enorme y tan poco asimilable, sino las formas puras de una creación tan orgánica como organizada.

Los antiguos griegos encontraron una palabra para expresar esto: Cosmos, que equivale al Universo agrupado desde el primitivo desorden en formas maravillosas. Una vez que esto queda claro, comprendemos ya qué viene antes y qué viene después en aquellas dos acepciones de figure que veíamos al principio. El arquitecto, con sus formas, puede regalar felicidad; y la función sigue a la forma.

Un traje bien hecho llevado por un hombre guapo, y la brillante sedosidad de un modelo femenino sobre las suaves curvas de una muchacha, son formas que unen a ambos para una función-puede decirse-más íntima.

El reclamo de las aves es también una forma con elementos auditivos y melodiosos. $Y$ esta forma atrae al pájaro-hembra de bello aspecto, que después genera e incuba. Una luciérnaga que zigzaguea de aquí para allá sobre las praderas en una tarde oscura es como una veloz locomotora que recuerda con su rápido fulgurar las formas de un baile excitante. Esta luz, este baile, no sirve como el resplandor de nuestros faroles para iluminar la calle o como el baile de nuestras reuniones sociales para la diversión; es el mensaje enviado a la luciérnaga hembra, y ella lo recibe. Se encuentran y procrean; en ese momento se apaga su luz, y esto es lo importante. Esto nos enseña que todo el rápido fulgor-forma-servía sólo para iniciar una función, la más importante función de las luciérnagas: perpetuar su especie.

Nosotros, nuestros pueblos, nuestras ciudades americanas, sufrimos este desorden, este caos, esta confusión en el campo de nuestra visión. Aquí presento otra escalofriante estadística del progreso: doce millones de americanos aguardan turno cada año en las salas de espera de los siquíatras. ¡Llegamos a preguntarnos dónde demonios encuentran sitio para aparcar su coche! $\mathrm{Y}$ este pequeño problema contribuye probablemente a su nerviosidad y a sus perturbaciones síquicas.

Creo necesaria una investigación sicológica sobre la influencia que la planificación de las ciudades, sus edificios y su tráfico, puede ejercer en la vida humana. Probemos a tomar la presión sanguínea en torno a la mejilla, y la transpiración alrededor del cuello de un hombre que 
sabe llegado el momento de girar hacia la izquierda en la congestión urbana de una ciudad, o de aquel otro que al llegar la noche se encuentra con el único acceso a su barrio inutilizado por unas obras. ¿Qué ocurre en su interior? Algo puedo adelantar. He tenido clientes en San Francisco, Filadelfia, Nueva York, Chicago, Dallas, y en Nueva Orleáns. Por todos sitios la nerviosidad general aumenta cada mes, $y$ hasta las pequeñas ciudades se empiezan a incorporar a esta guerra fría.

Lo grave es que no existe el progreso, sino millones de pequeños progresos separados que se aniquilan mutuamente. Los accidentes y las catástrofes no bastan para hacernos olvidar el legítimo orgullo que "nuestro" progreso nos causa. Inventamos pavimentos acústicos que absorben el crujido de los frenos, el gemir de la hojalata y el astilleo de los cristales. Tenemos cinturones de seguridad a precios rebajados; y cuando éstos no han sido eficaces, el mismo pavimento absorbe el olor de la sangre, que seca y escurre con rapidez. Poderosos y altivos creemos avanzar, y poderosos y altivos retrocedemos.

Uno de mis clientes, que vive en Contra Costa y conduce su coche todas las mañanas por el puente más grande del mundo, en dirección a San Francisco, me relató el otro día una maravillosa experiencia. La fuerza del progreso mordía ya su alma. Su automóvil se estropeó al acercarse al puente.. "Nunca había experimentado una sensación semejante" me dijo; "cuarenta mil coches se detuvieron detrás de mí durante veinte minutos." "Era una mañana preciosa. Podía ver el sol jugando sobre el agua de la bahía, si miraba hacia delante. Si miraba hacia detrás, por el espejo retrovisor, veía los parachoques brillantemente cromados. Todas las bocinas aullaban; me parecían muy alegres las de los coches lejanos, muy desagradables las de los cercanos. Todo el mundo quería llegar a su despacho. Aquello parecía bullicioso y feliz, como el trabajo en un "día de suerte". Me parece que todos aquellos que se muestran orgullosos por el progreso, tienen la misma lírica y convencida manera de mirar hacia delante 0 hacia detrás.

Los arquitectos y los proyectistas están encargados de disponer las condiciones vitales del hombre. ¿Deben servir a sus clientes, o deben también advertirles de los peligros que les acechan? A la hora de la verdad, nuestra resistencia biológica es sólo la que cabe en nuestro cuerpo, en ese cuerpo que llevamos tantos miles de años maquillando y adulterando. Todavía tenemos dos ojos y dos orejas; todavía conservamos el sentido de la temperatura y del equilibrio de nuestros primeros padres. No vayamos a olvidarlo.

Somos como niños en el marco maravilloso donde nuestra especie se ha desarrollado. $Y$ en ese marco, la función no sigue, no seguía a la forma; la belleza y la utilidad no eran conceptos diferentes, almacenados en distintos compartimientos, para que un empleado los pusiese en venta.

¿Dónde deja un árbol de ser hermoso y se convierte en útil? No existe tal separación en la naturaleza, ni en el aspecto externo de nuestra piel. No llevamos encima departamentos separados de recepción para la belleza y para la utilidad. Entre la cantidad de sentidos que se han descubierto últimamente (y sabemos ya que son muchos más de cinco), no se ha encontrado ninguno que podamos llamar "de la Belleza". Esta es, en realidad, una convención del lenguaje; y nos entra por todos los sentidos, mutuamente relacionados y fundidos con la materia del cerebro superior y con la actividad endocrina. Incluso una respetable cantidad de músculos intervienen cuando tocamos, vemos, olemos $u$ oímos belleza. El hombre es un conglomerado armónico y homogéneo, que no admite la división en departamentos. Es un sistema de fuerzas cerradas. $Y$ su arquitecto debe tenerlo en cuenta.

Conocer al hombre es la más antigua recomendación de los filósofos. Servirle sin conocerle sin comprenderle, es trabajo perdido.

"Empathy"-intuición para desnudar el alma de nuestro prójimo-es el mayor don que puede tener un arquitecto; y no será un verdadero arquitecto contemporáneo aquel que voluntariamente lo ignore. Sólo el año pasado se han publicado noventa y ocho mil boletines de investigación profunda sobre Biología Humana, en los periódicos más conocidos de Nueva York y Moscú. Leonardo de Vinci y los arquitectos humanistas del Renacimiento hubieran leído con gusto toda esta literatura. Para ellos el hombre era aún la medida de las cosas.

Debe serlo también para nosotros. Debemos conocerle para servirle mejor. Si queremos alojar a un oso blanco en un parque zoológico, tenemos que conocer los osos blancos, que entenderlos e-incluso-que amarlos.

¿Hemos concebido siempre nuestra arquitectura, nuestros departamentos y nuestras ciudades según este principio? Pon la mano sobre el corazón, y contesta. No, no hemos aplicado lo que sabemos a nuestra vida cotidiana, ni hemos encaminado nuestros conocimientos humanistas a la formación de un medio humano convincente. Nos ocupa demasiado tiempo el juego de emplear los nuevos materiales que se anuncian, de cobrar por esos proyectos que llamamos "arquitectura", y de pronunciar la palabra "hogar", pensando que el Estado ha concedido su préstamo. Pero la naturaleza humana obra de modo muy diferente todo este desbarajuste comercial y financiero. El arquitecto del mañana deberá conocer la base real y permanente del confort humano y de la supervivencia vital. El niño nace de la mujer. Este es su primer medio ambiental. Después pasa a ser un muchacho que aprende a vivir. Más tarde, un joven, un adulto $\mathrm{y}$, finalmente, un anciano. El individuo humano es-desde la cuna a la tumba-un pan de distintas capas, cocidas una sobre otra, en el fondo constitucional, en el horno caliente de la 


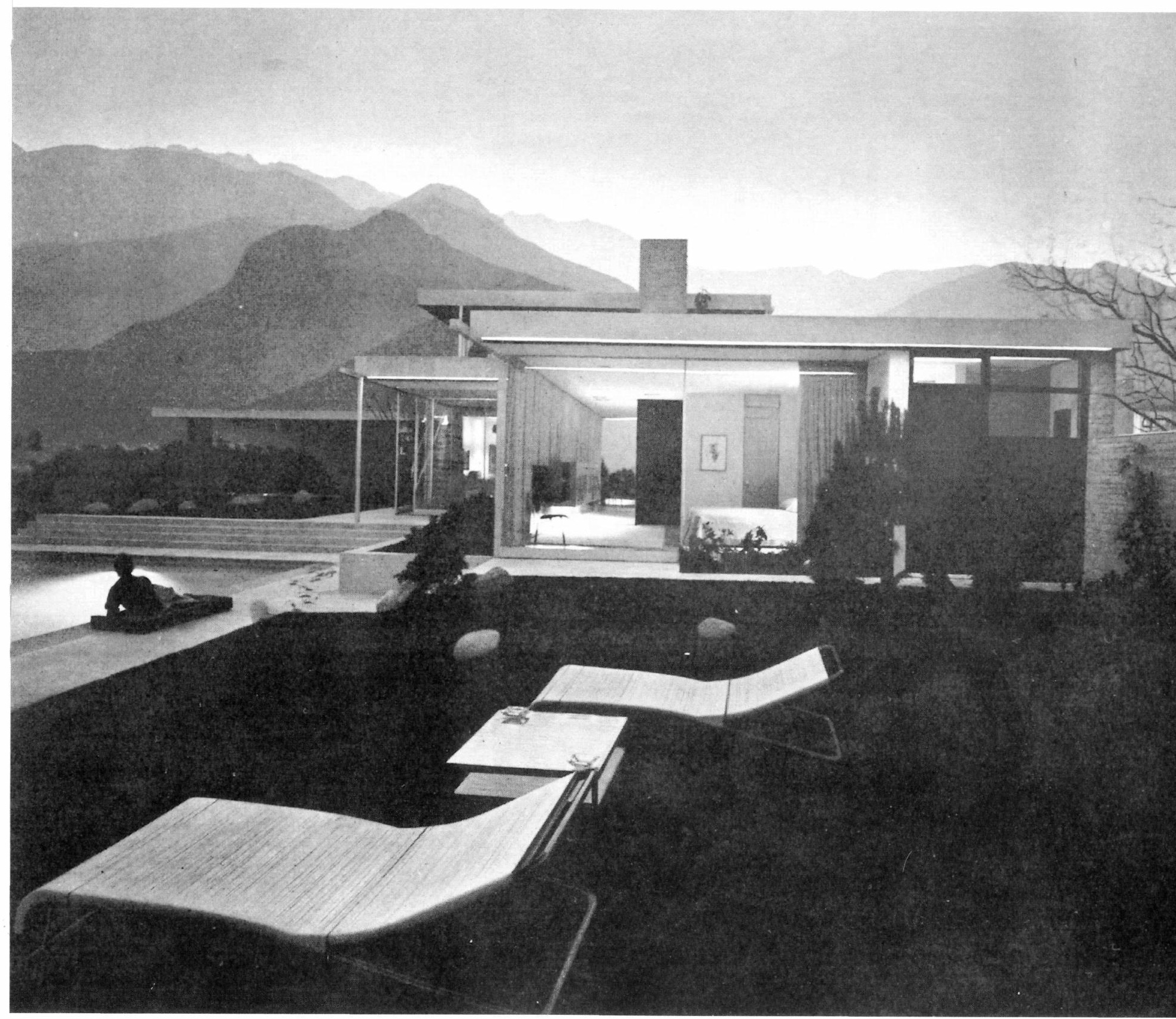

Residencia de Edgar Kaufman en Palm Spring, California. A la sencillez formal de la estructura se opone el contraste de las abruptas montañas del fondo, mientras que su transpa. rencia armoniza con la limpia superficie de gua de la piscina. 

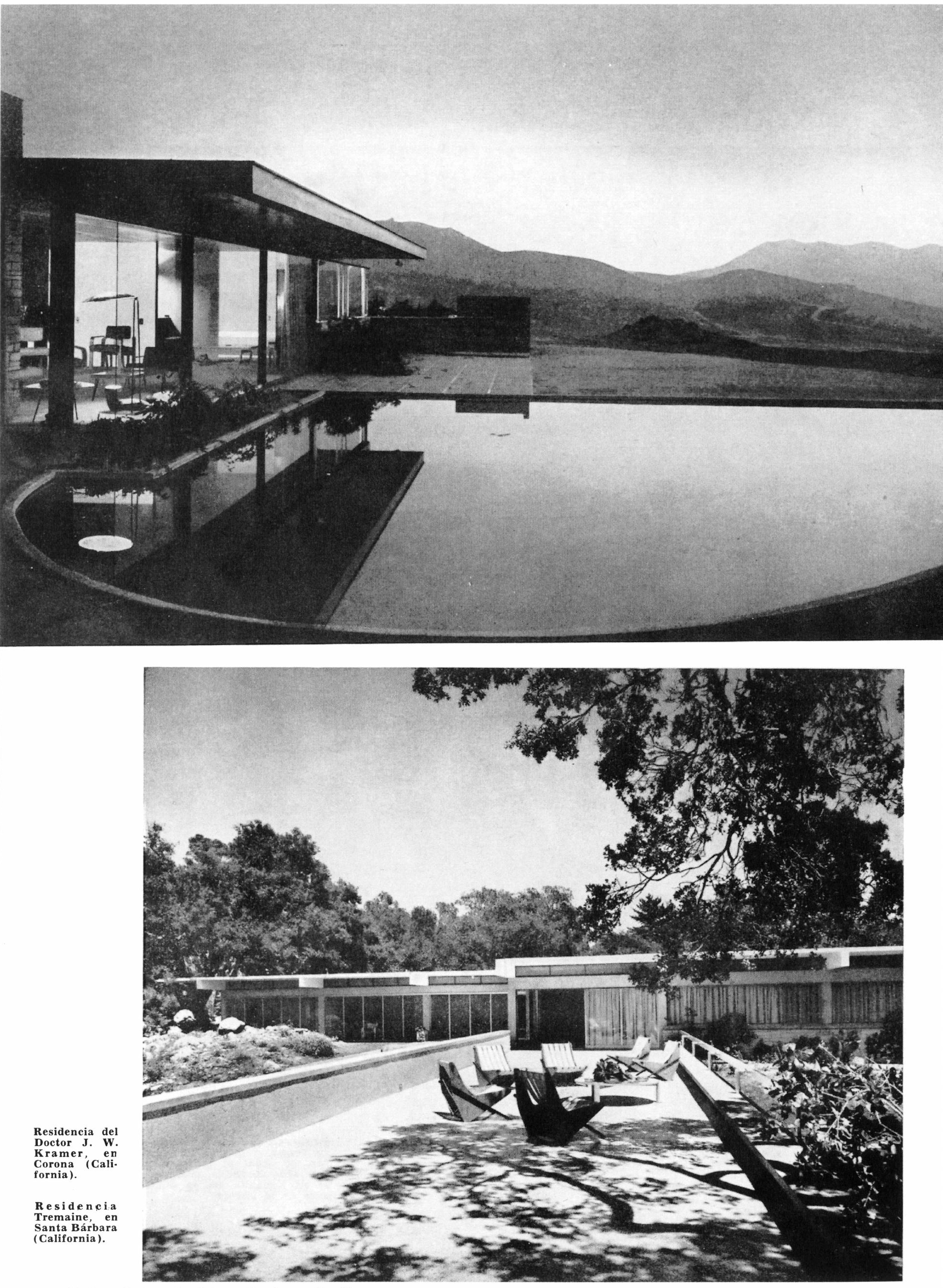

(c) Consejo Superior de Investigaciones Científicas Licencia Creative Commons 3.0 España (by-nc) 
experiencia humana, en el útero suave y poderoso. El destino biológico forma allí los factores esenciales genésicos. Los fisiólogos han llamado a estas capas "reflejos condicionados", porque el organismo y su comportamiento se modifica según las circunstancias del medio ambiente. Las fases posteriores y artificiales de este medio ambiente las realiza el arquitecto, y por eso se constituye en maestro peligroso del destino humano.

El medio ambiente originario está íntimamente fundido con el individuo biológico. Suponer una temprana separación entre medio ambiente e individuo, es un grave error.

El embrión primario camina despacio y delicadamente hacia el nacimiento. Su sentido interior auditivo, de posición y de aceleración, está estimulado suavemente por mínimas percepciones; del mismo modo, su sentido superficial del tacto recibe por todos lados la presión ligera del líquido uterino. Este líquido tiene una temperatura parecida a la de la sangre, y es-como ella-templado, constante, sin colisiones térmicas. Las diferencias de temperatura se las traerá la vida externa más adelante. Pero no las recibe en el período de gestación. No existe ninguna estimulación por ósmosis del gusto, y ni siquiera existe este sentido. Tampoco percibe olores. Las sensaciones auditivas de la vida exterior llegan muy confusamente a este "sancta sanctorum" de la maternidad. Así, el sentido del oído comienza sus funciones de una manera suave, sin estridencias ni ruidos violentos.

Los ojos están aún cerrados. No existe visión alguna. Sólo algunos días después del nacimiento, se abrirán para recibir los cambios de luz, sombra y color. Sin embargo, es una importante característica humana el hecho de que abra sus ojos mucho antes que los gatos recién nacidos. El hombre no se detiene en una prolongada ceguera tras el nacimiento. Algunos biólogos han llegado a pensar que el hombre nace menos desarrollado que el resto de los seres vivos, para que su cerebro se pueda alimentar y formar desde un principio con influencias y estímulos auténticamente externos; para que los billones de distintas células comiencen su maravillosa carrera a compás. El hombre-como individuo y como especie-depende de su medio ambiente. El joven ciervo o la jirafa están listos para andar desde el mismo nacimiento. El niño humano, por el contrario, con sus ojos abiertos, necesita una larga temporada para coordinar su sentido locomotor; transcurre mucho tiempo desde que el niño empieza a utilizar su vista -el más cerebral de sus sentidos-hasta que comienza a caminar por sus propios medios. El hombre es el animal más inteligente, y por eso está dotado con un infantilismo extremo, casi eterno. En él no es un signo patológico la lentitud de su formación física. Es su mayor problema y su máxima virtud.

Antes de surgir a la vida exterior, encontramos el hecho del nacimiento. Biológicamente, es dudoso que éste sea en sí un choque, un trauma-como lo llamaba Rank, el temprano discípulo de Freud-. Pero, ¿qué pasa después del nacimiento?

Hace unos minutos, un niño ha abierto sus ojos. Ahora yace en el sanatorio de maternidad con los ojos de par en par, mirando la brillante iluminación característica de los hospitales. Desde luego, una máscara en la cara de las enfermeras le protege de inoculaciones microbianas: es un tributo que rendimos a Pasteur. Al mismo tiempo, cuarenta y cinco niños más lloran en una habitación demasiado reverberante para los oídos de cualquier persona. Ningún animal - por inferior que sea- encierra a su hijo con otros cuarenta en un nido que huele a farmacia, o los balancea vertiginosamente por el aire al mudarle los pañales, o los enfría con un fuerte contraste termal entre la temperatura del embrión (que ha soportado nueve meses) y la del aire exterior. La diferencia que el recién nacido percibe entre el cuerpo de la madre y la sección infantil del hospital es enorme y estremecedora.

El niño-y su niñera y el partero-se entregan confiadamente a las manos del arquitecto del hospital. $\mathrm{Y}$ el arquitecto es tan precariamente poderoso, como inocente. Su práctica-terriblemente importante-sustituye-debe sustituir-el delicado cuidado con que el pájaro padre construye su nido, teniendo en cuenta hasta la más mínima influencia del árbol, del clima, del terreno. Justamente en aquella horquilla del árbol que reúna las cantidades apropiadas de sol y sombra, establecerá su nido-milagro, mínimo, compacto y apto para el necesario confort. Los pájaros y las abejas, los peces y las gallinas, sobreviven así mejor que el hombre, dotado y obsesionado por su poderoso cerebro, guardado, herido, ayudado y violado por un ser semejante a él, perteneciente al Colegio de Arquitectos. Todas las mañanas me repito esta consideración, y levanto mi dedo acusador para advertir a mi conciencia. Sí, un arquitecto puede perjudicar y ayudar. Un arquitecto puede influir de modo duradero en los elementos de nuestra individualidad. De nuestra individualidad que-por cierto-nos enseña la suprema ley de que las capas superiores de un ser vivo son más fáciles de modificar que las inferiores. Dicho con otras palabras: en una mujer o en un hombre-como en una casa-es más factible la sustitución del tejado que la de los cimientos. El arquitecto actúa sobre las capas superiores del niño, sobre su vida exterior, y no sobre su vida embrionaria. Por eso, es decisiva su influencia.

Pero tengamos cuidado con estas afirmaciones. ¡A fin de cuentas, la naturaleza humana se puede cambiar! Hablemos otra vez del niño. Pocas horas después del nacimiento, ya recibe alimentos. Cualquier cosa que toca su mejilla, le hace volver la cabeza. Con sus pequeños labios se agarra a todo lo que parece un pezón y empieza a chupar. Succiona, como una complicada bomba hidráulica, el líquido dulzón, de la misma temperatura de la sangre, que rezuma el pecho de la madre. Todo esto es una concatenación de reacciones primarias tan bien organizadas, que no parecen susceptibles de un cambio. Sin embargo, el hombre es capaz de cambiarse, alterando profundamente los instintos de su individualidad. Los seres humanos sustituyen más tarde la leche de la madre por la Coca-Cola burbujeante y por la cerveza amarga. Si 
el arquitecto no es capaz de modificar el modo de vida de una generación, por medio de las palabras, de los hechos o del medio ambiente, me imagino que no merece la pena serlo. Pero, sobre todo, no le debería estar permitido la práctica sobre sus colegas humanos, si no tiene en cuenta que existe una zona biológica detrás de la cual se pisa una finísima costra de hielo. Podemos, por medio de nuestro cerebro explosivo y desenfrenado, proyectar o imaginar una situación en que la vida humana haya desaparecido de la tierra, destruída con sucesivas irritaciones. acumulativas. La vida de nuestras ciudades no sufre a diario amenazas tan aparentes como las de una bomba termonuclear, pero se destruye constante y lentamente en medio de esta larga agonía de la paz. Los ingenieros transmiten grandes fuerzas por medio de tracciones analizadas, hasta el acero y el hormigón; pero el arquitecto debe considerar también las suaves transacciones de energía del sistema nervioso, los intimos transportes sanguíneos de la piel. Aquí tenéis la diferencia entre estas dos elevadas profesiones humanas. El hombre medio de hoy día tiene una idea definida sobre lo que es un ingeniero; pero los arquitectos son andantes enigmas, $y$ como tales los juzga el funcionario público, y los considera la Dirección de las Empresas constructoras.

Si las mariposas y los pájaros y los peces tropicales tienen un sentido para el color y para la forma, que podemos considerar primario, entonces San Francisco tenía razón, y todas las criaturas-hasta los seres humanos-somos hermanos.

Los edificios no se deben proyectar en exclusiva función de un rendimiento económico. Los edificios deben servir, además, para misteriosas satisfacciones dentro de fracciones temporales, tal como el nacimiento de una vida, o la experiencia de un amor. Del mismo modo que percibimos la elasticidad, la estructura y la forma, percibimos también el mundo arquitectónico en toda su peculiar complejidad; en un momento fundimos las reverberaciones solares con la luz y la sombra, el olor de la alfombra y del barniz con la pérdida de calor o de frío en el mármol. o con la helada sensación del acero inoxidable. Puede existir en todo esto una armónica unidad o un increíble desbarajuste. Tal vez usted, lector, no lo sabe, pero su casa le puede volver loco. Su arquitecto es capaz de pervertir a su mujer, de estropear sus niños y de destruir su matrimonio. Es capaz de acumular molestias diarias, aumentando la tensión familiar de día en día, interviniendo en las más delicadas relaciones de convivencia. El hecho de que la mayoría de la gente desconozca este peligro, no lo disminuye en absoluto. No es el coche que usted ve venir el que le atropella, sino el que no ha visto. Se puede uno acostumbrar a fumar opio y se apasiona por él, hasta que un buen día cualquier médico le avisa del peligro y le obliga a desintoxicarse.

El hombre y la mujer que quieren construir, deben darse cuenta de que una casa no es simplemente un conjunto de elementos estilísticos. Los últimos avances de ingeniería y revestimiento cambiarán muchas veces durante el largo período de amortización. Pero algunas de nuestras necesidades básicas se edifican sobre nuestras virtudes y nuestras faltas, incluso por medio de instintos heredados $y$ transmitidos por muchas generaciones anteriores, y no podemos olvidar estas necesidades a la hora de construir nuestro hogar. El arquitecto tiene que ser un biólogo de altura; y así, sus obras sobrepasarán en mucho los puros efectos de cosmética exterior.

Y ya que hablamos de las faltas humanas, y de su comprensión, voy a relatar algo que me aconteció en cierta ocasión: Un señor y una señora-que proyectaban su futuro hogar-vienen a verme. Mr. Smith, nada más sentarse, plantea la cuestión de cuánto le va a costar el proyecto. ¿Qué préstamo es conveniente solicitar? ¿Cuánto tiempo invertirá en la elaboración del proyecto? Esta es la nefasta conversación práctica que a diario tenemos que soportar. Como si el dólar para la construcción de casas no disminuyera su valor con cada cohete que enviamos a la luna. Durante la conversación, observo que Mrs. Smith está aburrida, enfadada y nerviosa. Como un águila enfurecida busca un hueco en la conversación y ataca. "La semana pasada-dice-había un baile de sociedad con la familia Joneses, y entré en su tocador. Allí he visto un papel de pared que era una preciosidad." Posiblemente porque había bebido un par de copas, su memoria estimulada conserva la imagen del papel, con una considerable carga emocional. "Sus colores eran tales y tales." Mrs. Smith habla ahora de colores, de esquemas de colores, de colores para alfombras, para manteles, para tapices, para almohadas.

Mientras habla, observo a su marido. Ha tenido que callarse, y ahora está exasperado, nervioso, aburrido, fastidiado, rabioso por esta charla poco práctica sobre el color. Mira a su mujer con desprecio, porque está gastando su precioso tiempo-lleno de redondas y detalladas cifras-hablando de colores.

Yo tomo la palabra, y explico con suavidad, utilizando cifras concretas, que el $0,02 \%$ de todas las mujeres tienen anomalías de percepción visual para los colores. Eso es poco, si se compara con los hombres, de los cuales hasta un seis por ciento sufre recepción defectuosa de los colores. El daltonismo es-como el afeitarse por las mañanas-una característica del sexo. En otras palabras. Este hombre lleva veinte años casado, y no se ha dado cuenta todavía de que el hombre está construído según normas diferentes a las de la mujer. Por eso le explico ciertos hechos científicos de la vida cotidiana, y les reconcilio para que puedan ser más felices después.

El hogar no es, en realidad, una percha donde cuelgas al arquitecto, y ya nunca desaparece de ella. Pero sí-en espíritu-se queda contigo para siempre. Mucho tiempo después de haberle pagado los honorarios, permanece a tu lado, invisible, lleno de misteriosa influencia, veinticuatro horas cada día, trescientos sesenta y cinco días cada año durante tres o cuatro decenios. Esta es una amortización muy larga que todos tienen que pagar. Realmente, tu vida se puede hacer distinta, si tu arquitecto no conoce y ama a la Humanidad. 

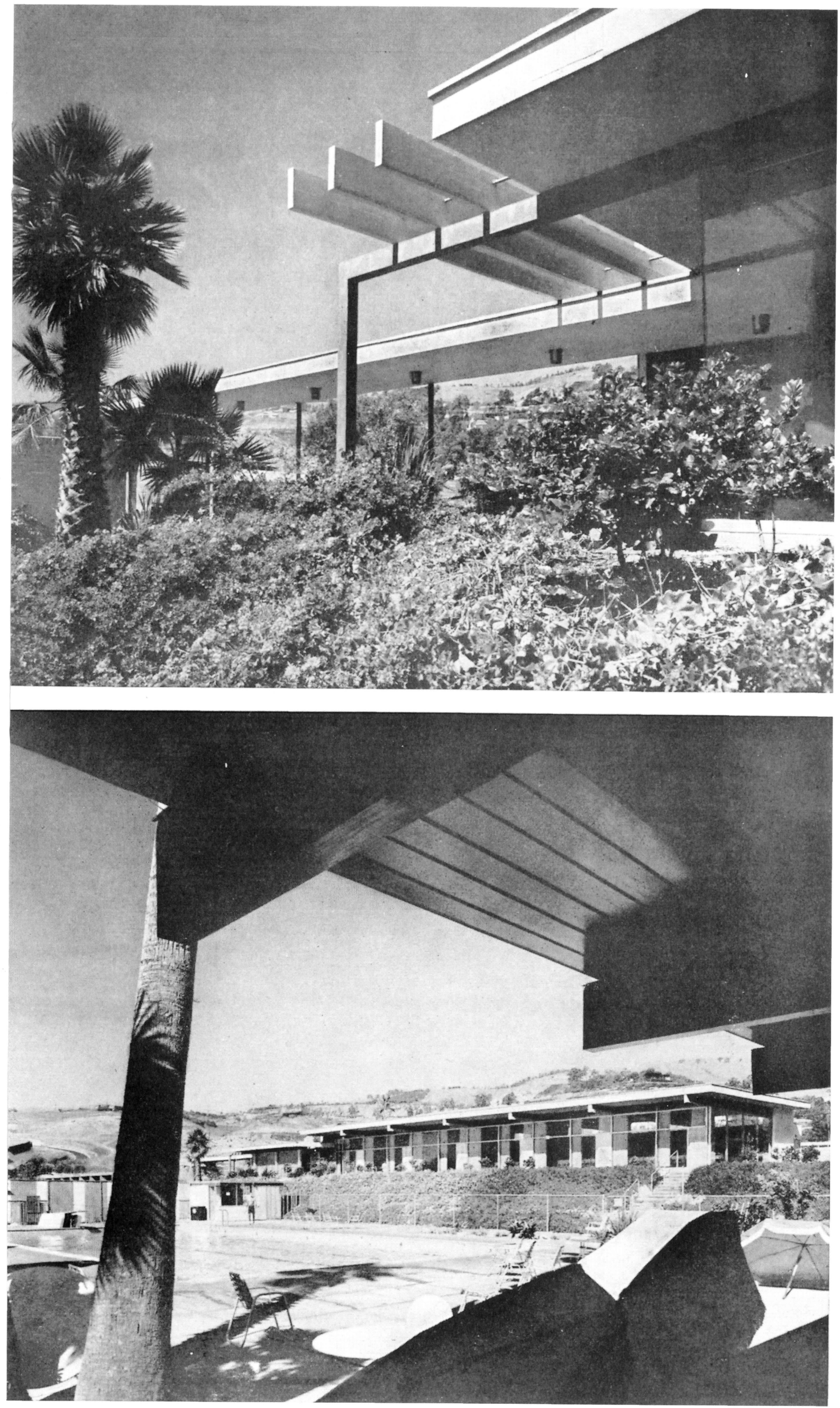

San Pedro - Hacienda Hotel. California. Paos cubiertos enlazan las distintas unidades residenciales con las instalaciones generatacames la que desjunto al ciscina Junto al Club Poly- 


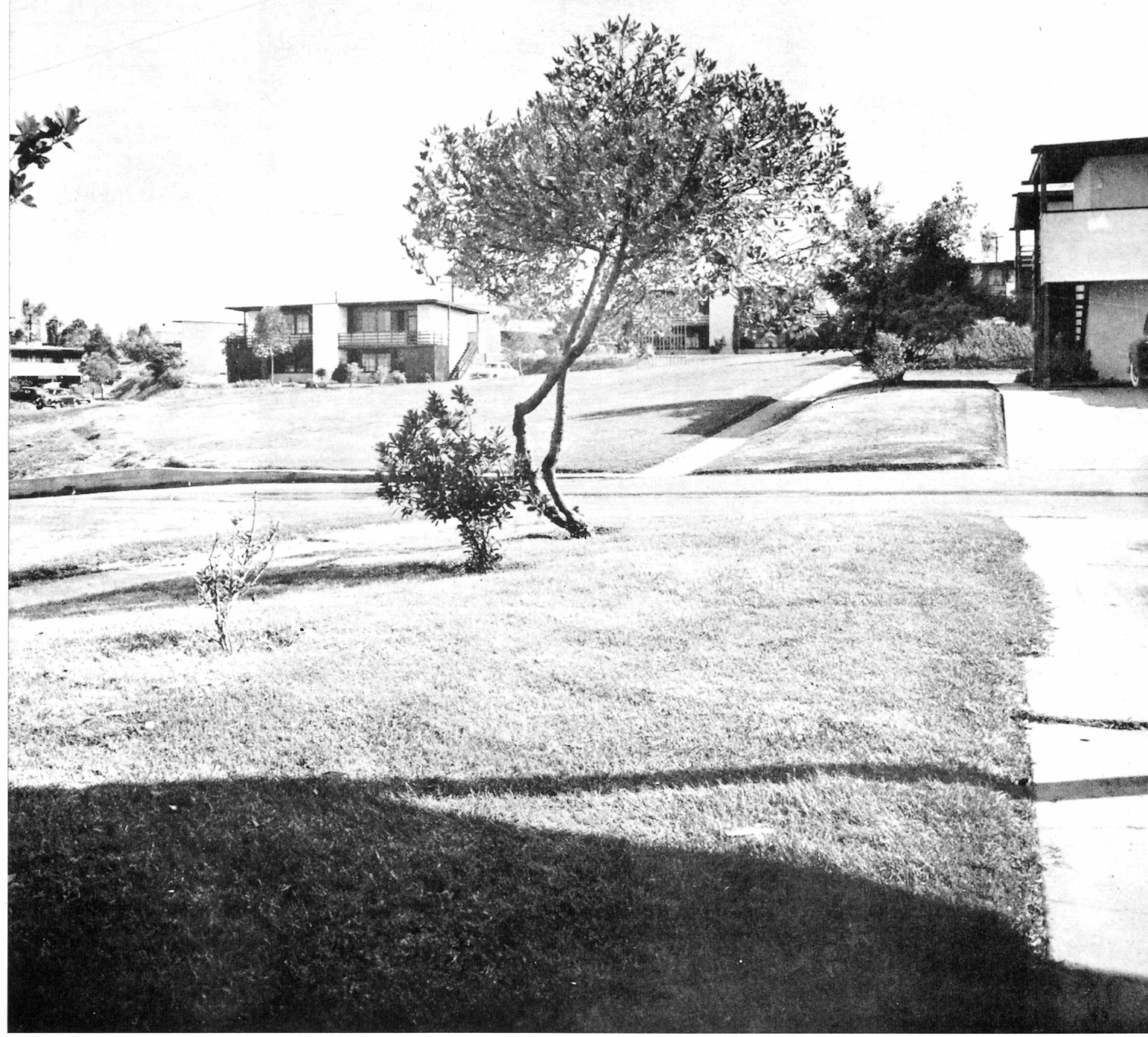

